\title{
Nuclear imaging in the diagnosis of infective endocarditis
}

We agree with the conclusions established by Mahmood et al. ${ }^{1}$ - that PET/CT is a useful adjunctive diagnostic tool in the evaluation of infective endocarditis (IE), especially involving prosthetic valve(s). They also stated $\mathrm{PET} / \mathrm{CT}$ has the potential to detect clinically relevant extracardiac foci of infection and may result in more appropriate management decisions.

Another modality of nuclear imaging-white cell scans-is recognized in the current guidelines of the European Society of Cardiology ${ }^{2}$ as being more specific in the diagnosis of IE. It is not as likely to yield nonspecific sternal radiotracer uptake in patients who have recently undergone cardiac surgery. Further, a number of pathological conditions can mimic the pattern of focally increased fluorodeoxyglucose uptake that is typically observed in IE, such as active thrombi, soft atherosclerotic plaques, vasculitis, primary cardiac tumors, cardiac metastasis from a non-cardiac tumor, post-surgical inflammation, and foreign body reactions.

In addition, it is more easily available in many centers-especially those (such as ours) which does not have PET/CT available. Do the authors of this metaanalysis have any relevant information on the use of white cell scintigraphy in this context?
J Nucl Cardiol 2020;27:1049.

$1071-3581 / \$ 34.00$

Copyright (c) 2019 American Society of Nuclear Cardiology.

\author{
Joseph C. Lee, MBBS, FRACP, FAANMS, ${ }^{a, d}$ \\ Yong $S$. Wee, MBBS, FRACP, , $^{b}$ \\ Robert L. Horvath, MBBS, FRACP, FRCPA $A^{c, d}$ \\ ${ }^{a}$ Department of Medical Imaging, The Prince Charles Hospital, \\ Chermside, QLD 4032, Australia \\ ${ }^{b}$ Department of Cardiology, The Prince Charles Hospital, Chermside, \\ QLD 4032, Australia \\ ${ }^{c}$ Department of Infectious Diseases, The Prince Charles Hospital, \\ Chermside, QLD 4032, Australia \\ ${ }^{d}$ Faculty of Medicine, University of Queensland, St Lucia, QLD 4072, \\ Australia
}

Disclosures Joseph C. Lee, Yong S. Wee, and Robert L. Horvath have no conflicts of interest to declare.

\section{References}

1. Mahmood M, Kendi AT, Ajmal S, Farid S, O'Horo JC, Chareonthaitawee P, et al. Meta-analysis of 18F-FDG PET/CT in the diagnosis of infective endocarditis. J Nucl Cardiol 2019;26:922-35.

2. Habib G, Lancellotti P, Antunes MJ, Bongiorni MG, Casalta JP, Del Zotti F, et al. 2015 ESC Guidelines for the management of infective endocarditis: The Task Force for the Management of Infective Endocarditis of the European Society of Cardiology (ESC). Endorsed by: European Association for Cardio-Thoracic Surgery (EACTS), the European Association of Nuclear Medicine (EANM). Eur Heart J 2015;36:3075-128.

doi:10.1007/s12350-019-01819-4

Publisher's Note Springer Nature remains neutral with regard to jurisdictional claims in published maps and institutional affiliations. 